\title{
Tensions in Stakeholder Relations for a Swedish Football Club A Case Study
}

\author{
Junghagen, Sven
}

Published in:

Soccer and Society

DOI:

10.1080/14660970.2016.1267621

Publication date:

2018

License

Unspecified

Citation for published version (APA):

Junghagen, S. (2018). Tensions in Stakeholder Relations for a Swedish Football Club: A Case Study. Soccer and Society, 19(4), 612-629. https://doi.org/10.1080/14660970.2016.1267621

Link to publication in CBS Research Portal

\section{General rights}

Copyright and moral rights for the publications made accessible in the public portal are retained by the authors and/or other copyright owners and it is a condition of accessing publications that users recognise and abide by the legal requirements associated with these rights.

Take down policy

If you believe that this document breaches copyright please contact us (research.lib@cbs.dk) providing details, and we will remove access to the work immediately and investigate your claim. 


\section{Tensions in Stakeholder Relations for a Swedish Football Club: A Case Study}

\section{Sven Junghagen}

Journal article (Accepted version)

Cite: Tensions in Stakeholder Relations for a Swedish Football Club: A Case Study. / Junghagen, Sven. In: Soccer and Society.

This is an Accepted Manuscript of an article published by Taylor \& Francis in Soccer and Society on 14 December 2016, available online:

http://www.tandfonline.com/10.1080/14660970.2016.1267621

Uploaded to Research@CBS: August २०17 


\title{
TENSIONS IN STAKEHOLDER RELATIONS FOR A SWEDISH FOOTBALL CLUB - A CASE STUDY
}

\author{
Sven Junghagen, $\mathrm{PhD}$ \\ Dept of Management, Politics and Philosophy, \\ Copenhagen Business School, Denmark.
}

\begin{abstract}
Swedish Football is an industry not yet being as commercial as the big leagues and is regulated in terms of ownership of clubs. This implies a need for management of stakeholder relations for a Swedish football club. This paper identifies important stakeholders in Swedish football and discusses the multitude of - sometimes conflicting - objectives in managing these relations. The empirical base of the study is founded in a case study of Malmö FF, one of the dominant clubs in Sweden, with a qualitative single case research approach. Data is collected by means of semi-structured interviews and participant observations. The results of the study show a number of tensions as paradoxes for stakeholder management, suggest management dispositions to reconcile these paradoxes and suggest areas for further research.
\end{abstract}

Keywords: Swedish professional football, Clubs, Stakeholder analysis, Management, Strategy

\section{INTRODUCTION}

Contemporary football (soccer) in the postmodern era ${ }^{1}$ builds on the logic of a multimillion industry where football has become big business involving the conventional business strategies traditionally used by corporations ${ }^{2}$. There is, however, an important difference between football clubs and traditional private sector corporations that has to be acknowledged. For most stakeholders, the position in the league at the end of the season is the main indicator of success, not the financial performance ${ }^{3}$. This leads to a need to find a balance between the shareholder and the stakeholder perspective in management of football clubs. Even though professional football in the postmodern era is turning an increased focus towards the shareholder perspective, it is utterly important to maintain a strong focus on 
stakeholders, where supporters and the local community may be the most important ones to maintain the viability of a football $\mathrm{club}^{4}$.

This paper will account for a study in the Swedish context, where the stakeholder perspective becomes even more relevant for two major reasons: The relatively limited commercial strength of the top tier league Allsvenskan, and the governance structure due to Swedish regulations. In comparison to the aggregate revenue of the top 20 clubs in Europe amounting to $€ 5.4$ billion $^{5}$, the 16 clubs in Allsvenskan only generate an aggregate revenue of approximately $€ 150$ million $^{6}$. Since professional football clubs in Sweden are 'owned' by members, which will be further elaborated on later in this paper in the section 'Supporters and Members', there is an even stronger incentive for a focus on stakeholders ${ }^{7}$. This implies that the balance between shareholder and stakeholder perspective could be significantly different in Sweden than in the big European leagues, which makes the Swedish case interesting to discuss.

This paper takes a single-case study approach of Malmö FF to explore the relations between a club and its stakeholders. The relevance of Sweden as a case has been argued for above, and the reasons for choosing Malmö FF as a case will be presented later. The overall approach of the study is inspired by Friedman, Parent and Mason ${ }^{8}$, being an empirical study especially focusing on the following dimensions:

- Defining the stakeholders;

- Examining organisation-stakeholder relationships;

- Defining issues;

- Defining potential responses.

There are, however, certain limitations to this approach. When defining issues to be solved, it will be shown that problems are interconnected to other problems and their solutions, which implies that in this complex stakeholder situation, problems are wicked ${ }^{9}$. Therefore, it will be shown that relations to individual stakeholders cannot be managed separately, but are interconnected and should be treated accordingly.

\section{StAKEHOLDERS IN THE SWEDISH FOOTBALL LANDSCAPE}

This section will set the scene for the coming discussions by defining the Swedish football landscape, with the different stakeholders influencing performance of clubs. The football club itself and the other clubs constitute the competition in the football landscape. In a world where it is all about the sports competition, collaboration is not necessarily needed, but in a world were football is so much more than the game itself collaboration comes more natural. One could make a claim that in an industry where football is becoming more and more a total experience and entertainment industry, what is good for football in general is good for all individual clubs. 
Since the scope of this paper is to discuss the business of football rather than the aspect of competitive sports, competing clubs will not be addressed. Furthermore, there are a number of associations, which indirectly influence the manoeuvrability for an individual club, e.g. FIFA, UEFA, SvFF (The Swedish Football Association), and SFSU (Swedish Football Supporters United). These associations will also be excluded from the discussion; the focus will instead be on stakeholders having a more direct influence on the operations of a club. In an international context, the role of the owner and other business interests would be a natural component of a stakeholder analysis. However, in the Swedish context, these discussions become obsolete given the aforementioned regulations for membership based sport clubs. These regulations are seen as a major barrier to commercialisation of football in Sweden, since a club cannot be bought by rich investors.

\section{Supporters and Members}

As was argued in the introduction to this paper, one of the most important stakeholders is the supporter - or the fan. One could of course argue that members and supporters constitute two different stakeholder groups, but the difference between the groups lies mainly in the voting power of members and this difference will also be discussed hereunder. However, since members are also assumed to be supporters of the club, members and supporters will be treated as one stakeholder group.

As suggested by e.g. Mullin, Hardy and Sutton ${ }^{10}$, the football consumer market is not one homogeneous mass displaying identical consumer behaviour, but rather like any other consumer market where segmentation and classification of consumers is important. Hunt et.al. ${ }^{11}$ propose a classification of sports fans into the following categories: 'Temporary', supporters that have a time limited affection to a certain club due to e.g. a certain player on the team; 'local', supporters of a club because of the identification with a geographical area; 'devoted', this supporter is not constrained by time and place; 'fanatical', whose behaviour goes a step beyond the one expressed by the devoted fan, but still socially accepted; and 'dysfunctional', supporters that see being a fan as the primary method to identify his or her self to others and to his or her own self. The difference to devoted and fanatical fans is not the fan-like behaviour, but to the degree the behaviour is deviant, disruptive and anti-social. Tapp and Clowes ${ }^{12}$ suggest a classification into the following three categories: 'Fanatics', supporters whose self-image is very much related to football or the club, chanting for 90 minutes; 'regulars', supporters regularly attending matches but not actively supporting the team; and 'casuals', event consumers who attends football for the sheer entertainment of football and the total experience at the stadium. 
The commitment and the consumer involvement of the these categories can range from the club being the way the active supporter expresses his or her identity to the entertainment consumer who is not so interested in the outcome of a match, but rather the total experience. This total experience is created not only by football event on the pitch, but also by the fanatic supporters, hence becoming customers and co-creators of the same event ${ }^{13}$. Other factors that attract the non-fanatic spectators are the uncertainty of the outcome of the match ${ }^{14}$, the form of the team, and the attractiveness of the opponent team ${ }^{15}$. Cross and Henderson ${ }^{16}$ further claim that events during match day do not affect gate takings, which is counter argued by Van Uden ${ }^{17}$, who presents the idea of the football club as a 'total experience' entertainment company managing the experience not directly related to the event on the pitch. This is further supported by Biscaia, Correia, Rosado, Maroco and Ross ${ }^{18}$ that present a study of hedonistic behaviour in relation to the total event on match day.

In all of the above presented spectator categories, one will find members of the club as well as non-members, giving the individual an ownership status on top of the consumer status, which in turn adds complexity in the relations of the club. There are regulated conditions for the ownership of a professional football club in Sweden, which have an impact on the manoeuvrability of the club. A membership based club has the right to transform itself into a publically listed company, but with the limitation that at least $51 \%$ of the voting rights have to be allocated to the membership based club, to protect the interests of club members. The positive effect of this rule is that the traditions of a club and its anchorage among the member population are ensured. The negative effect is that the attractiveness for financially powerful investors is claimed to be reduced, since a strong investor typically wants a clear and concise decision power to come with the investment ${ }^{19}$.

\section{Media}

A substantial part of the revenue stream of a club comes from TV broadcasted matches. The distribution model for revenues based on TV rights differs from country to country, but in Sweden the model is flat, meaning that the distribution of revenue from TV rights to the individual club is not significantly affected by team success, spectator interests, or other differentiators ${ }^{20}$. It was shown that the overall revenue was distributed as TV revenues $22 \%$, Gate takings 35\%, and Commercial revenues $43 \%$. There are of course variations among the different clubs in the study, but it shows that $65 \%$ of the revenue stream for the average Swedish professional football club is generated by TV revenues and commercial revenues.

An increased exposure in media does have a positive effect on the brand equity of the clubs but there is not just a local and domestic competition for fandom, but also a strong global competition. Given the 
globalisation of television and a highly frequent exposure of dominant clubs with iconic international star players, clubs are not just competing with the local rivals, but with international clubs for fandom ${ }^{21}$. Furthermore, the emergence and convergence of new media have led to an obsolescence of both social contexts and concepts of location in supporter traditions ${ }^{22}$.

Apart from being an important part of the revenue stream for clubs, media also traditionally play an important role on forming opinions in the public. Print and broadcast media has previously been the dominant source for reports and analyses for a mass audience, but the media climate is also changing beyond the globalisation effects mentioned above. The emergence of Web 2.0 has changed the concept of media from having control over content from sender to receiver to being a situation where the interconnectedness enables a situation where content is co-created in interaction between senders and audience. Social media and online communities are playing an increasingly important role for the sociocultural factors surrounding professional football, which leads to a complex definition of media as a stakeholder ${ }^{23}$. Media-Supporter relations have changed radically, especially for supporters with high involvement, where traditional mass media play a subordinate role in relation to new online media ${ }^{24}$. In Sweden, a social media platform called Svenskafans.com has gained significant popularity among supporters and is an important forum for information and debates both in and out of season.

\section{Sponsors}

The relation to sponsors is important for a club in terms of revenue streams. It has been estimated that the average Swedish premier club gets as much as $28 \%$ of the operating income from sponsors, which makes it the most important source for operating income ${ }^{25}$.

Sponsorship objectives are manifold, but the most common objective is to raise brand awareness among consumers. However, non-consumers are also often targets, including employees, channel members, community, and even competitors with the aim to block the opportunity for a competitor to sponsor. ${ }^{26}$

A very typical way of claiming value for sponsors in Swedish football is to offer exposure on the team shirts, which often leading to a high number of visible sponsors. However, this is a quite harmful path to follow since it has a negative effect on club image and wasteful for the individual sponsors $^{27}$. Exposure on match day has a positive effect on sponsor brand loyalty $^{28}$, but it seems like it is quite important to strive for a balance between the number of sponsors and the potential turnover when attracting sponsors. Several studies have shown that the typical shirt sponsor programme is based on the expectation on short term returns ${ }^{29}$. Short term transactions however rarely lead to success, but rather the long term relationship where interactions and commitment even stretches beyond the 
context of the sponsorship ${ }^{30}$. It has also been shown that investments in more complex sponsor programmes, such as platinum and gold sponsorships, do lead to higher levels of brand awareness effects ${ }^{31}$. Regardless of what is the actual effect of a sponsorship, the club has to take the perception of the sponsor into account. Henseler, Wilson and Westberg ${ }^{32}$ have proposed a sponsorship index consisting of six components which affect sponsor companies' perception of the positive effect on brand equity:

(1) The level of brand exposure;

(2) The amount of coverage;

(3) The club's quality;

(4) The advertising opportunities the sponsor receives

(5) Certain privileges granted to the sponsor; and

(6) The exclusivity given to the sponsor.

However, the club-sponsor relation is not just about trying to maximise financial transaction, but also to understand non-financial effects. Sponsorship programmes does not necessarily just lead to positive effects, it has been shown that a main sponsor of one club risk to experience a harmful effect on brand equity among rival supporters ${ }^{33}$. The passion for a club can definitely translate into loyalty for a sponsor brand ${ }^{34}$. This relation between commitment to the club and the orientation towards brands sponsoring the club has also been shown by Shaw and MacDonald ${ }^{35}$, which in turn implies that a successful relationship to sponsors is also very dependent to a successful management of the relation to committed supporters.

\section{Community}

As for basically all organisations in all industries, social responsibility has become an issue for football clubs and associations. In the business literature, two main schools of thought can be identified. On the one hand, taking responsibility could be seen as a means to gain competitive advantage $^{36}$ and on the other hand, responsibility could be seen as something which is done because it is the right thing to do without ulterior motives $^{37}$. Studies have shown that an active engagement in CSR projects do affect the overall performance of clubs positively ${ }^{38}$. It has further been concluded that an active involvement in community activities has a positive effect on the relation to all stakeholders of a club ${ }^{39}$.

One could always argue that football clubs always have taken a social responsibility in their own community, by e.g. organising sports activities for the youth population. However, social responsibility is not just about a public health project, but goes beyond this. There are e.g. substantial problems with hooliganism connected to the rivalry between professional 
clubs. This is not necessarily a problem for the clubs alone, or associations alone, but this is a community problem, where all involved actors must assume a responsibility. A certain phenomenon has, however, been identified. That is one of non-dysfunctional supporters that are to a certain extent seduced by the thrilling culture of hooligans and therefore do not oppose to their actions. These supporters have been labelled 'hoolifans' ${ }^{40}$.

\section{Mapping the Landscape}

Freeman and Reed ${ }^{41}$ propose an approach to stakeholder analysis, including a mapping of stakeholders in a 'real world' stakeholder grid. It builds on the notion that there are two dimensions: the stake or interest of a stakeholder, and the power of a stakeholder. Figure 1 summarises the discussion so far in a stakeholder grid for a Swedish football club.

\begin{tabular}{|c|c|c|c|}
\hline & $\begin{array}{c}\text { Formal or Voting } \\
\text { Power }\end{array}$ & $\begin{array}{c}\text { Economic } \\
\text { Power }\end{array}$ & $\begin{array}{l}\text { Political } \\
\text { Power }\end{array}$ \\
\hline $\begin{array}{l}\text { Equity } \\
\text { Stake }\end{array}$ & $\begin{array}{l}\text { - Members } \\
\text { - Directors }\end{array}$ & & $\begin{array}{l}\text { - Dissident } \\
\text { members }\end{array}$ \\
\hline $\begin{array}{l}\text { Economic } \\
\text { Stake }\end{array}$ & & $\begin{array}{l}\text { - Sponsors } \\
\text { - } \text { Customers }\end{array}$ & $\begin{array}{l}\text { - } \text { Community } \\
\text { - Media } \\
\text { - Supporters } \\
\text { - Supporter Clubs }\end{array}$ \\
\hline Influencers & - SvFF & $\begin{array}{ll}\text { - } & \text { SEF } \\
\text { - } & \text { SFSU }\end{array}$ & $\begin{array}{l}\text { - UEFA } \\
\text { - } \text { FIFA }\end{array}$ \\
\hline
\end{tabular}

Figure 1. A Stakeholder Grid for a Swedish Football Club.

The remains of this study will not address issues related to all different stakeholders, but will focus on the relationship with the stakeholders where the club has a potential to affect the relation itself, and where the stakeholder has an equity or economic stake, also defined as the 'social network' of a football club ${ }^{42}$ :

- Supporters and members;

- Media and sponsors;

- The surrounding community.

It has already been argued for viewing supporters and members as one group. The reason for grouping media and sponsors in a group together even though these two have different power bases is that these two constitute the main revenue stream which is not related to the expense of the individual football consumer.

The question is how a club can manage these relations with sometimes conflicting goals, in a way that the three goals of a football club are fulfilled? 
The empirical findings presented in the remains of this study are based on three data collection methods:

- Secondary data sources; such as documentation, annual reports, club files, and press articles

- Semi structured interviews with key employees of Malmö FF

- Participative observation over a period of two years, 2011-2012.

Participative observation as a method can be problematic in terms of validity. In this case, where the author is part of one of the stakeholder groups - members and supporters - there is an obvious risk of being biased based on the personal frame of reference. In order to avoid this, participation has been as 'observer as participant', to combine involvement with a detachment in order to stay objective ${ }^{43}$. In practice, this means that the author did not actively take part in debates in social media or other forums for interaction during the time period of data collection.

\section{MALMÖ FF - A BRIEF INTRODUCTION TO THE CASE}

Malmö FF (MFF) is one of the dominant football clubs in Swedish football and could be characterised as a 'big club in a small league', which makes it interesting for a case study. MFF was founded back in 1910 with football as the only sports discipline in the club. A number of other disciplines were later introduced, but as of today the club has again focused on football only. History is important as for most clubs. Malmö FF is traditionally the club for the working class. Throughout the years, a strong atomistic culture has been built up with a long-lived mantra of "it is us against all others" "4. In 1931, MFF took the step up to Allsvenskan and since then the club has only been relegated twice, in 1933 and 1999.

MFF is the most successful club in Sweden in terms of titles, with 19 league wins and 14 cup wins. The resulting mentality of the successful history is also reflected in the vision of the club:

'MFF's vision is to be the leading football club in the Nordic with recurring participation and success in the European tournaments by means of winner mentality, team spirit and professionalism'

Swedish professional football is a fairly young concept in comparison to other national leagues. MFF was the first club in Sweden introducing semiprofessional players in the team back in 1989, which signals the pioneering spirit of the club in relation to the development of Swedish football.

In 2009, MFF opened a new partially owned stadium: Swedbank Stadion, or as it is called in international games: Malmö New Stadium. This marked a turning point for the club where professionalism should no longer just imbue internal operations, but also the relations to external stakeholders. 


\section{Stakeholder Relations for MALmö FF}

The following section will account for specific findings in the case study exploring the relations between MFF and the above identified interesting stakeholder groups.

\section{Supporters and Members}

MFF has a deliberate disposition to the different categories of members and supporters, but it is not formalised in an explicit strategy. On match day, there are very specific categories of spectators, divided into the different sections of the stadium. With that said, the club is also quite aware of the risks with a too explicit segregation in terms of entry fees. Anyone paying a higher price for attending a match also has to perceive that he or she is receiving a higher value.

An important issue is to deal with the balance between the different categories of supporters. MFF has previously failed in the communication with the active supporters and has not been able to see how these supporters are not just spectators, but also co-producers of the event:

'Some of our event consumers are actually attending matches, not mainly for the match itself but, to enjoy the atmosphere created by the active supporters'

MFF occasionally also adds on to the total experience at the stadium by means of add-on events in relation to matches. These activities have had a positive effect in relation to the casual supporter categories, but there are issues in relation to fanatics. A strong opinion has been observed among significant fanatics, who express scepticism about events that are not aligned with their traditional view of football.

In order to be able to handle the complex situation, MFF is now working on developing manuals and process descriptions for the treatment of members and supporters of different categories. Members do have a privileged status and there is a deliberate differentiation of information to different categories, but this is not formalised. A dialogue forum is established to continuously maintain the dialogue with the different formations of active supporters. All are part of the 'MFF Family' and all have voice and a saying. The club has become more humble in relation to the active supporters, with an increased understanding of engagement and a better ability to handle criticism as an effect.

The dialogue is not always without friction, though. Some measures taken by the club, induced by incidents during or around matches, are by fans considered to be unfair collective punishment leading to manifestations during matches and an intense debate in social media. The aim of the restrictions has been to maintain a higher level of safety for spectators or the surrounding community, but decisions regarding the responsibility have a flipside when it comes to the relation to supporters. 
I am serious about the membership in Malmö FF! Us members, who are Malmö FF, can and will affect everything in our club. We do not want a couple of suits run the show when they couldn't care less about us supporters. So make sure to make your voice heard, become a member in Malmö FF already now! Your voice and vote is important!" ${ }^{46}$

Another dimension that has caught the attention of members and supporters is the financial performance of the club. MFF made a long term investment in the new stadium - Swedbank Stadion - which opened in 2009. These heavy investments put a financial constraint on the club the following years which in turn led to a stronger emphasis on the financial performance. This led to a lot of speculation on the balance between financial performance and the fact that MFF is a member based organisation taking part in the sports movement.

A final important issue is the general fandom. Even though it is claimed that everyone in Malmö has some kind of opinion about MFF, it is hard to compete even on a local level for the commitment of fans:

We do not just compete with other Swedish clubs for fandom, but rather

with the larger international clubs from the big leagues in Europe. You see more Barca and Chelsea jerseys in schools than ours. ${ }^{47}$

These fans of international clubs might attend MFF's matches as regular supporters or event consumers but the lack of active support does have a negative consequence for the competitive parity of the MFF brand in relation to merchandise. There is an expressed hope that the community activities described further below might lead to positive effects in this aspect.

\section{Media and Sponsors}

The relations with media are certainly complex, since they constitute a source of revenue as well as a potential partner in brand building of the club. When it comes to the revenue generation, this is mainly tied to the TV/Pay TV fees. As stated above, MFF does not have control over neither the negotiation of fees, nor the distribution of revenue. These decisions are made on central level by the Swedish Football Association. MFF has one of the strongest brands in Swedish football, is among the top clubs in terms of match attendance, and generates more interest in broadcasted matches than most other clubs. Still, it is impossible for any club in Sweden to individually control revenue streams from media that are strongly connected to the brand equity of the club ${ }^{48}$. If this would have been possible, a club like MFF would be able to affect the annual net profit substantially, which in turn would have quite positive effects on operations.

Media is furthermore a source of brand equity by means of non-paid public relations. Apart from the on-going reporting of results and reviews of matches, both print and broadcast media also produce editorial in-depth comments on clubs and football in general. In the 2011 season, with the 
turbulence in relation to e.g. interrupt matches, media tended to focus more on the negative turbulence rather than the positive elements of football clubs.

It seems like media is more interested in hooliganism and negative aspects of the supporter culture, rather than commenting on all the good things we accomplish, both for the club and society, ${ }^{49}$

This situation had the implication that e.g. gate takings declined during 2011, where the tendency was that especially the amount of event consumers was reduced.

An in-house study carried out by MFF over three years showed that as many as 75 per cent used the MFF website as their source of information before a match, while the use of mass media was much more limited, approximately 25 per cent for both print and broadcast media.

The journey towards a comprehensive sponsor strategy started in 1999, when MFF was relegated from Allsvenskan and were to play in the second league for the first time since 1933. The goal was clear; MFF should be back in the first league again immediately. In this process 'The Network' (Nätverket) was born, a number of local companies joining forces to strengthen the financial platform for the club to realise this goal. Many of the sponsors involved were joining in because of a strong emotional relation to the club, which was more or less symptomatic for all sponsors of the club. Malmö FF changed their sponsor strategy in relation to the opening of the new stadium in 2009.

We are deliberately focusing on long term sponsorship and partner agreements, where sponsors make decisions with their brain rather than with their heart ${ }^{50}$

Before this deliberate change, as many as 144 sponsors were exposed at the same time in the stadium. The new policy explicitly implies that maximum 16 sponsors are exposed in the stadium on match day, ranging from naming rights of the stadium to official partner status.

During the 2012 season, MFF did not have a kit sponsor, which was highly appreciated by many devoted fans seeing this as a manifestation of the traditional football ideals far away from the post-modernity of today's football. The reality is that MFF overestimated the sponsor market and the premium price which could be charged in 2011, including exposure in UEFA Champions league and Europa League, was seen as too high for potential sponsors in 2012.

We asked for approximately one million $€$, but I have now realised that it was overestimated and that the realistic price is around balf a million $€$. We are to make efforts to sell it for 2013, but we are not to scrawl the shirts full with logos ${ }^{51}$

An interesting observation about the 2011 kit sponsor is the colour of the logo. The sponsor's logo is red, and in the first matches, the logo was printed on the sky blue shirts in red. This induced a lively debate in several 
social media platforms, where the general opinion was that it was more or less a contamination of the shirts to have a large red logotype. After just a couple of games, the print logo was changed to white, which is seen as harmonising with the club's sky blue and white colours.

\section{Community}

MFF is one of the strongest brands on a local and regional level. They therefore consider themselves to have a strong responsibility to engage in community issues. A strong ambition is to be not just the club of Malmö, but also the club of Scania, an administrative province in southern Sweden. One means to achieve a higher level of engagement outside Malmö is to play friendly matches and U21 matches in smaller towns around Scania. There is also a belief that a strong commitment in the local community can help prevent some of the negative aspects and social problems in relation to football fandom.

'As a membership based organisation, one could state that we have a community responsibility by default. ${ }^{52}$

One major social problem which is directly connected with professional football is hooliganism. It is not realistic to believe that MFF will be able to solve the different issues underlying this societal problem. One way to approach this is by inclusion, rather than exclusion. The problem is not just related to conflicts on match days, it is important to channel the strong engagement into a positive supporter culture together with other involved actors.

An example from the 2012 season was the prelude of the away derby against the regional rival Helsingborgs IF. This derby has in recent years been defiled by problems with hooliganism and perceived insecurity for the general public as a consequence. Police authorities required that transportation of MFF supporters to Helsingborg should be regulated to approve the event. MFF agreed to that in order for a MFF supporter to get access to the away team tribune, they had to travel to Helsingborg with certain mandatory busses going directly to the arena and they would not be allowed to mark their presence by means of a traditional march through Helsingborg city. This agreement caused a lot of turmoil among supporters and the club's loyalty towards its supporters was questioned. After threats of boycott or filling the arena in the home team sections, a compromise was reached but a number of opinion makers among supporters still claimed that the trust between club and supporters was breached.

Apart from reactive responses to problems, MFF also engages in proactive social commitment. Previously, MFF has not communicated any social activities externally, with quite limited influence on the relationship with stakeholders. In 2010, a decision was made to organise all social activities in an overall programme: Himmelsblå Hand (A Skyblue Hand). The short-term expected results of the programme are mainly: 
- A stronger visibility of the social commitment of MFF, and hence a positive influence on all stakeholder relations.

- A possibility to attract sponsors of social projects, who would otherwise not sponsor a football club.

In a long-term perspective the following expected effects are:

- Fostering and education will lead to reduced problems with hooliganism and the promotion of a more positive supporter culture.

- The MFF brand will be strengthened as a regional actor in the Scanian community.

Initially the programme has to be explicitly backed up by the MFF brand, but the ambition is that Himmelsbla Hand will be able to function as a stand-alone brand of the MFF portfolio in the future. Any kind of measure to determine effects of social projects and initiatives would be highly subjective, and as for many other organisations, it is hard to determine the outcome of CSR, but it is still done.

\section{Conclusive Discussion}

So far, the following parts of the Friedman, Parent and Mason ${ }^{53}$ framework have been completed: Defining the stakeholders; and examining organisation-stakeholder relationships. When it comes to defining issues, it is unavoidable to first mention a stakeholder, around whom a lot of the above accounted for observations revolve: The supporter. Supporters have been defined as maybe the most important stakeholder, and without the strong interest for football, devotion to clubs and iconic players, football would not be what it is today.

However, the relation to supporters is highly interdependent on relations to other stakeholders. Sponsors expect to achieve brand equity effects rather than just contributing to a club based on affection. It has been shown that there are indeed positive effects to gain, especially among highly committed supporters. The actual effect in the customer group which is not as committed to the club, e.g. the casual supporter, is however not as clear. The question is then how the club reacts to non-acceptable behaviour among dysfunctional supporters who in fact often are part of the fanatic supporter category who also contributes to the production of the total experience at the stadium. Media often report about the negative aspects of supporters and the question is to what extent sponsors are willing to associate their brand with a club having problems with dysfunctional supporters. On the other hand, if the club takes an active stand against certain expressions for supporting the club, this can create a distance 
between the club and its supporters, which in turn might have a negative effect for sponsors as well.

As was stated, MFF is trying to establish sponsorship agreements that do not just build on emotional appeals but is more driven by a business rationale. It is important to point out in the Swedish context that is crucial to establish a proper balance between the two. According to international studies, a solid long term relationship with sponsors does not focus on the transactional elements, and classic business logic. However, these studies are typically based on findings from the top leagues in Europe, where the solid exposure and brand effects for a sponsor are more evident. In Sweden, clubs cannot claim the same level of natural effect and hence they need to establish relationships with sponsors that are driven by transactional claims as well as emotional claims. The collaboration with PUMA is good example, were a long term kit supplier agreement has led to the collaboration in the MFF Shop, a combination of a merchandise shop and a PUMA shop.

On the other hand, it has been hard to establish a long term sponsor relation for the kit sponsorship. The sponsor of the 2011 season chose not to continue the commitment for 2012. This could tentatively be explained by a less favourable cost-benefit-ratio in a season without international exposure, but it certainly highlights the necessity to establish the long term relation to eliminate short term financial vulnerability for the club.

\section{IMPLICATIONS}

The final part of the empirical study of stakeholders involves a definition of potential responses to the issues. As it has been shown, a professional football club is confronted with a number of different stakeholders, and a quite complex set of relationships. Minoja ${ }^{54}$ suggests an ambidextrous approach to stakeholder management, where he identifies three important dichotomies in the decision regarding taking a stakeholder's interests into account:

- 'whether' - yes or no

- 'when' - long term or short term

- 'how' - customised or standardised

However, this normative statement relates to a traditional business setting where the conflict between the stakeholder and shareholder value is more evident than in the case of football clubs.

In the complex landscape of stakeholder relations, there are a number of conflicting interests in the creation of stakeholder value as well, which can be seen as tensions in stakeholder management. Even though there are strong limitations in terms of generalizability in a single case study like this, there are still some important tensions that can be identified. The question 
club management has to ask itself is how to deal with a tension when being confronted with two diverse pressures from different stakeholders. Tensions can be met in different ways ${ }^{55}$ : As solving puzzles, where it is possible to find 'the best' optimal solution; as resolving dilemmas, making a choice which is 'either-or'; or making trade-offs, where the optimal solution is found in the balance between the two pressures; but a fruitful way to approach a tension is to look at it as a paradox where the solution - by means of a dialectical approach - aims to "get the best of both worlds" in multiple innovative reconciliations.

\section{Tension 1: Consumption and Co-Production}

Taking a business perspective on the football club implies that the important customer group are attendees at matches generating gate takings and related sales. However, as has been shown, the situation is far more complex than for a "traditional" event producer. Some of the consumers are also owners of the business, by means of membership in the club and they together with others are co-producers of the total event that can be sold to the casual attendees.

The casual attendees can and should be treated as customers, including the understanding the hedonistic consumption patterns and the parameters affecting repeat purchase behaviour. The fanatics should also be treated as customers, but the recognition as fans involves a closer dialogue with these fans, where the question is not just about what the club can do to optimise the event for this customer group, but also how the club and the fanatics jointly can optimise the event for casuals. In terms of direct turnover, the fanatics might not be important from a revenue viewpoint but they are contributing so strongly to the atmosphere of the event that measures should be taken to facilitate their expression of fandom.

A typical segmentation of a customer population implies that the more you pay the more service you get. Fanatics are typically not the big spenders in the stadium, but they do contribute anyway by means of coproduction. To recognise this, the club should consider measures to enhance the perceived relationship equity. The paradox to be resolved is that the same event is perceived radically different in different customer groups, and one of these customer groups is also co-producer of the event for the other group.

\section{Tension 2: Club Identity and Sponsorships}

In the postmodern era of football, sponsors play an important role for the financial performance of the club. This does not automatically imply that the club should get as many sponsors as possible, but rather an adequate portfolio of sponsors. The main target group for sponsors is the group of supporters being affectionate in various degrees to the club. This affection is quite closely related to the identity of the club and hence should the sponsor portfolio also be to a certain extent aligned to the identity of the 
club. In the case of MFF, there are strong traditions of the working class and the local foundation in Scania. The paradox to be resolved is that on the one hand the club wants to attract sponsors who act logically rather than affectionately, and on the other hand the primary target group for the sponsors act affectionately.

\section{Tension 3: Supportership and Club Responsibility}

The strong support from the fanatic supporters is a dual edged sword. On the one hand, it empowers players on the pitch and creates a strong atmosphere in the stadium on match day. On the other hand, some expressions are considered as dysfunctional in relation to the norm system in society, and sometimes illegal. This typically leads to sanctions from clubs and a high level of dissatisfaction from the devoted supporters, since sanctions are often regarded as collective punishment as response to individual misbehaviour. The paradox to be resolved is that the club has to act responsibly in relation to the surrounding community, especially regarding issues that are closely related to the match event. At the same time, most of these issues are related to the expressions of supportership of fanatics, who are important for the creation of the total experience of the event.

\section{Tensions between Tensions}

Even though only three tensions have been highlighted, it becomes clear that the tensions are not isolated paradoxes, but they are in fact interrelated. This adds further to the wickedness of the problems with stakeholder management. Picture the following example: Given the misbehaviour of dysfunctional supporters, the Club chooses to introduce restrictions of some kind at the stadium on match day. This is a decision taking tension 3 into account. This decision will immediately have a connection to tension 1 as well as tension 2 . If the affectionate supporters react strongly against the decision, because it is seen as collective punishment, will sponsors react to the fact that the Club is not treating their potential customers well? Furthermore, if the fanatics choose to be passive instead of active supporters during the event, how will that affect the experience for the casual event customers? The example is hypothetical, but the wickedness of the problem is real.

It can be concluded that the fanatic supporters constitute a very important stakeholder group, and they are a part of all three tensions. This does not mean that the interest of supporters should be met in all decisions, which would be to treat the tension as a dilemma, searching for the eitheror solution.

\section{Implications for Management}

It has been shown that stakeholder relations for football clubs are indeed wicked problems. There are tensions between motives among different 
stakeholders, and even if one of these tensions is resolved, it might be interconnected or in conflict with another identified tension. The suggestion for a solution is to use a dialectic approach, trying to get the best of two worlds. Mason and Mitroff ${ }^{56}$ present two major principles for decision making when confronted with wicked problems:

- The broad participation of affected stakeholders, directly and indirectly, in the decision process

- Decisions should be based on a wider spectrum of information gathered from a large number of diverse sources.

This should be considered for all major decisions that can have an impact on stakeholder relations. Forums for continuous dialogue with key stakeholders are essential, as well as a strong understanding of different stakeholders among directors and management of the club.

\section{SUgGESTIONS FOR FURTHER RESEARCH}

As was stated in the section above, there are certain limitations with this study in terms of external validity beyond the case studied. In order to confirm the identified tensions, either a multiple case research design or a cross sectional survey design would contribute with more generalizable results. Furthermore, this study takes an approach to stakeholder relations with the football club as subject. The discussion also implies that a dialectal approach is needed to find solutions to the paradoxes embedded in the identified tensions. Future research could therefore study the relations from the perspective of both parties in order to be able to conclude on normative statements for concrete responses to stakeholder interests.

1. Giulianotti, Football: a Sociology of the Global Game

2. Madichie, "Management Implications of Foreign Players"

3. de Heij, Vermeulen and Teunter, "Strategic Actions in European Soccer"

4. Hamil, Holt, Michie, Oughton and Shailer, "The Corporate Governance of Football Clubs"; Michie and Oughton, "The Corporate Governance of Football Clubs"

5. Jones, Football Money League 2014

6. Sahlström, Analys av Allsvenska Klubbarnas Ekonomi

7. Spear, "Governance in Member-Based Organisations"

8. Friedman, Parent and Mason, "Building a Framework through Stakeholder Theory" 
9. Rittel, "On the Planning Crisis"; Rittel and Webber, "Dilemmas in a General Theory of Planning"; Mason and Mitroff, Challenging Strategic Planning Assumptions

10. Mullin, Hardy and Sutton, Sport Marketing

11. Hunt et.al., "Classifying Sports Fans"

12. Tapp and Clowes, "Segmentation Possibilities for Football Supporters"

13. Mehus, "The Diffused Audience of Football"

14. Forrest and Simmons, "Outcome Uncertainty and Attendance Demand"

15. Cross and Henderson, "Strategic Challenges in the Football Business"

16. Cross and Henderson, "Strategic Challenges in the Football Business"

17. Van Uden, "Transforming a Football Club"

18. Biscaia, Correia, Rosado, Maroco and Ross, "Football Spectators" Satisfaction and Behavioural Intentions"

19. Gammelsæter, Storm and Söderman, "Diverging Scandinavian Approaches to Football"

20. Olsson, "Benchmark." Slutrapport Allsvenskan

21. Sandvoss, $A$ Game of Two Halves

22. Ruddock, Hutchins, and Rowe, "Contradictions in Media Sport Culture"

23. Hutchins, Rowe, and Ruddock, "It's Fantasy Football Made Real"

24. Cleland, "The Media and Football Supporters"

25. Sahlström, Analys av Allsvenska Klubbarnas Ekonomi

26. Thompson and Speed, "A Typology of Sponsorship Activity"

27. Mikhailitchenko, Tootelian, and Mikhailitchenko, "Saturation Levels for Sponsorship Logos"

28. Vale et al., "The Impact of Sponsorship"

29. Chadwick and Thwaites, "Short-term and Long-term Commitment"

30. Bühler, Hefferman, and Hewson, "The Soccer Club-Sponsor Relationship"

31. Vale et al., "The Impact of Sponsorship"

32. Henseler, Wilson and Westberg, "Managers' Perception of Impact on Brand Equity"

33. Bergkvist, "The Flipside of the Sponsorship Coin"

34. O'Keeffe and Zawadska, "Does Passion for a Team Translate into Sales"

35. Shaw and MacDonald, "Season-ticket Holder Satisfaction"

36. e.g. Porter and Kramer, "Creating Shared Value"

37. e.g. Shamir, "The Age of Responsibility"; Margolis and Walsh, "Misery Loves Companies"

38. Walker and Kent, "Do Fans Care?"

39. Wallace, "An Insider's Look"

40. Rookwood and Pearson, "The Hoolifan" 
41. Freeman and Reed, "Stockholders and Stakeholders"

42. Andersson, Spela Fotboll bondjävlar!

43. Kawulich, "Participant Observation"

44. Andersson, Spela Fotboll bondjäular!

45. Interview with MFF Supporter Liaison Officer

46. Public appeal on Facebook in September 2012 from a significant supporter

47. Interview with MFF Communications Director

48. www.framtidsgruppen.nu, 2012-02-27

49. Interview with MFF Communications Director

50. Interview with MFF Sales Director

51. MFF Managing Director during an open meeting for members, Nov. 2012

52. Interview with MFF Supporter Liaison Officer

53. Friedman, Parent and Mason, "Building a Framework through Stakeholder Theory"

54. Minoja, "Stakeholder Management Theory"

55. De Wit and Meyer, "Strategy: Process, Content, Context"

56. Mason and Mitroff, Challenging Strategic Planning Assumptions

\section{REFERENCES}

Andersson, Torbjörn. Spela fotboll bondjävlar! Del 1. [Play Football Peasants!] Stehag, SE. Symposion, 2011

Bergkvist, Lars. "The Flipside of the Sponsorship Coin: Do You Still Buy the Beer When the Brewer Underwrites a Rival Team?". Journal of Advertising Research, 52(1) (2012): 65-73.

Biscaia, Rui, Abel Correia, António Rosado, João Maroco and Stephen Ross. "The effects of emotions on football spectators' satisfaction and behavioural intentions." European Sport Management Quarterly. 12, no. 3 (2012): 227-242.

Bühler, André W., Troy W. Heffernan, and Paul J. Hewson. "The soccer clubsponsor relationship: identifying the critical variables for success." International Journal Of Sports Marketing \& Sponsorship 8, no. 4 (2007): 291-309.

Chadwick, Simon, and Des Thwaites. "Distinguishing between short-term and long-term commitment in football shirt sponsorship programmes: towards a matrix of management implications." International Journal Of Sports Marketing \& Sponsorship 7, no. 3 (2006): 163-179.

Cleland, Jamie. "The media and football supporters: a changing relationship." Media, Culture \& Society, 33 no. 2 (2011): 299-315. 
Cross, John, and Steven Henderson. "Strategic challenges in the football business: a SPACE analysis." Strategic Change 12, no. 8 (2003): 409_ 420.

De Heij, Ron, Patrick Vermeulen, and Linda Teunter. "Strategic actions in European soccer: Do they matter?." Service Industries Journal 26, no. 6 (2006): 615-632.

De Wit, Bob, and Ron Meyer, Strategy: Process, Content, Context. $4^{\text {th }} \mathrm{ed}$. Hampshire, UK: Cengage Learning EMEA, 2010

Forrest, David, and Robert Simmons. "Outcome uncertainty and attendance demand in sport: the case of English soccer." Journal Of The Royal Statistical Society: Series D (The Statistician) 51, no. 2 (2002): 229-241.

Freeman, R. Edward, and David L. Reed. "Stockholders and Stakeholders: A New Perspective on Corporate Governance." California Management Review 25, no. 3 (1983): 88-106.

Friedman, Michael T., Milena M Parent, and Daniel S. Mason, "Building a framework for issues management in sport through stakeholder theory." European Sport Management Quarterly, 4 no. 3 (2004) 170190.

Gammelsæter, Hallgeir, Rasmus K. Storm, and Sten Söderman, "Diverging Scandinavian Approaches to Professional Football." In The Organisation and Governance of Top Football across Europe: an Institutional Perspective edited by Hallgeir Gammelsæter, and Benoit Senaux,. Oxon, UK: Routledge, 2011

Giulianotti, Richard. Football: a sociology of the global game. Oxford, UK: Polity Press, 1999

Sean, Hamil, Holt Matthew, Michie Jonathan, Oughton Christine, and Shailer Lee. "The corporate governance of professional football clubs." Corporate Governance: The International Journal Of Effective Board Performance 4, no. 2 (2004): 44-51.

Henseler, Jörg, Bradley Wilson, and Kate Westberg. "Managers' Perceptions of the Impact of Sport Sponsorship on Brand Equity: Which Aspects of the Sponsorship Matter Most?" Sport Marketing Quarterly 20, no. 1 (2011): 7-21.

Hunt, Kenneth A., and Terry Bristol. "A conceptual approach to classifying sports fans." Journal Of Services Marketing 13, no. 6/7 (1999): 439452.

Hutchins, Brett, David Rowe, and Andy Ruddock. "It's Fantasy Football Made Real": Networked Media Sport, the Internet, and the Hybrid Reality of MyFootballClub.” Sociology Of Sport Journal26, no. 1 (2009): 89-106.

Jones, Dan, ed. Football Money League 2014. Sports Business Group at Deloitte. Manchester: Deloitte, 2014

Kawulich, Barbara B. "Participant Observation as a Data Collection Method." Forum: Qualitative Social Research 6, no. 2 (2005): 1-22. 
Madichie, Nnamdi. "Management implications of foreign players in the English Premiership League football." Management Decision 47, no. 1 (2009): 24-50.

Margolis, Joshua D., and James P. Walsh. "Misery Loves Companies: Rethinking Social Initiatives by Business." Administrative Science Quarterly 48, no. 2 (2003): 268-305.

Mason, Richard O., and Ian I. Mitroff. Challenging Strategic Planning Assumptions: Theory, Cases \& Techniques. New York: John Wiley \& Sons, 1981

Mehus, Ingar. "The diffused audience of football." Continuum: Journal Of Media \& Cultural Studies 24, no. 6 (2010): 897-903.

Michie, Jonathan, and Christine Oughton. "The Corporate Governance of Professional Football Clubs in England." Corporate Governance: An International Review 13, no. 4 (2005): 517-531.

Mikhailitchenko, Andrey G., Dennis H. Tootelian, and Galina N. Mikhailitchenko. "Exploring saturation levels for sponsorship logos on professional sports shirts: a cross-cultural study." International Journal Of Sports Marketing \& Sponsorship 13, no. 4 (2012): 267-281.

Minoja, Mario. "Stakeholder Management Theory, Firm Strategy, and Ambidexterity." Journal Of Business Ethics 109, no. 1 (2012): 67-82.

Mullin, Bernard J., Hardy Stephen, and Sutton William A. Sport Marketing. 2nd ed. Leeds: Human Kinetics Europe, 2000.

O'Keeffe, Michael, and Joanna Zawadzka. "Does passion for a team translate into sales for a sponsor? The Irish case." Journal Of Sponsorship 4, no. 2 (2011): 190-196.

Olsson, Lars-Christer. "Benchmark" Slutrapport Allsvenskan. ["Benchmark" Final Report Swedish Premier League] Föreningen Svensk Elitfotboll, SEF. 2008

Porter, Michael E., and Mark R. Kramer. "Strategy \& Society: The Link Between Competitive Advantage and Corporate Social Responsibility." Harvard Business Review 84, no. 12 (2006): 78-92.

Porter, Michael E., and Mark R. Kramer. "Creating Shared Value." Harvard Business Review 89, no. 1/2 (2011): 62-77.

Rittel, Horst. "On the Planning Crisis: Systems Analysis of the "First and Second Generations"”. Bedriftsokonomen 8. (1972): 390-396

Rittel, Horst, and W. Webber. "Dilemmas in a General Theory of Planning." Policy Sciences 4, no. 2 (1973): 155-69.

Rookwood, Joel, and Geoff Pearson. "The hoolifan: Positive fan attitudes to football 'hooliganism'." International Review For The Sociology Of Sport 47, no. 2 (2012): 149-164.

Ruddock, Andy, Brett Hutchins, and David Rowe. "Contradictions in media sport culture: The reinscription of football supporter traditions through online media." European Journal Of Cultural Studies 13, no. 3 (2010): 323-339. 
Sahlström, Kjell. Analys av Allsvenska Klubbarnas Ekonomi 2013. [Analysis of Swedish Top Tier Clubs Finances 2013]. Svenska Fotbollförbundet, 2014

Sandvoss, Cornel. A Game of Two Halves, Football, Television, and Globalisation. Comedia. London: Routledge, 2003

Shamir, Ronen. "The Age of Responsibilization: On Market-Embedded Morality." Economy And Society 37, no. 1 (2008): 1-19.

Shaw, Robin N., and Heath McDonald. "Season-ticket holder satisfaction and sponsor-related behaviour: evidence of a positive relationship." International Journal Of Sports Marketing \& Sponsorship 7, no. 4 (2006): 318-325.

Spear, Roger. "Governance in Democratic Member-Based Organisations." Annals Of Public \& Cooperative Economics 75, no. 1 (2004): 33-59.

Tapp, Alan, and Jeff Clowes. "From "carefree casuals" to "professional wanderers": Segmentation possibilities for football supporters." European Journal Of Marketing 36, no. 11/12 (2002): 1248-1269.

Thompson, Peter, and Richard Speed. "A Typology of Sponsorship Activity." In International Perspectives on the Management of Sport edited by Milena M. Parent, and Trevor Slack. Burlington, MA: Elsevier Academic Press, 2007

Vale, José, Elisabete Serra, Vera Teixeira Vale, and José Carvalho Vieira. "The impact of sponsorship on a football team's brand equity." Journal Of Sponsorship 2, no. 3 (2009): 267-280.

van Uden, Jacoo. "Transforming a football club into a 'total experience' entertainment company: implications for management." Managing Leisure 10, no. 3 (2005): 184-198.

Walker, Matthew, and Aubrey Kent. "Do Fans Care? Assessing the Influence of Corporate Social Responsibility on Consumer Attitudes in the Sport Industry." Journal Of Sport Management 23, no. 6 (2009): 743769.

Wallace, Chris. "An insider's look at - and love for - pro basketball." In Inside the Minds: The Business of Sports, edited by Aspatore Books Staff, 2747. Boston, MA: Aspatore, Inc., 2004 